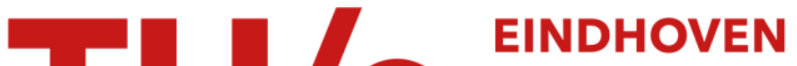 UNIVERSITY OF TECHNOLOGY
}

\section{Destocking, the bullwhip effect, and the credit crisis : empirical modeling of supply chain dynamics}

Citation for published version (APA):

Udenio, M., Fransoo, J. C., \& Peels, R. (2013). Destocking, the bullwhip effect, and the credit crisis : empirical modeling of supply chain dynamics. (BETA publicatie : working papers; Vol. 438). Technische Universiteit Eindhoven.

Document status and date:

Published: 01/01/2013

\section{Document Version:}

Publisher's PDF, also known as Version of Record (includes final page, issue and volume numbers)

\section{Please check the document version of this publication:}

- A submitted manuscript is the version of the article upon submission and before peer-review. There can be important differences between the submitted version and the official published version of record. People interested in the research are advised to contact the author for the final version of the publication, or visit the $\mathrm{DOI}$ to the publisher's website.

- The final author version and the galley proof are versions of the publication after peer review.

- The final published version features the final layout of the paper including the volume, issue and page numbers.

Link to publication

\section{General rights}

Copyright and moral rights for the publications made accessible in the public portal are retained by the authors and/or other copyright owners and it is a condition of accessing publications that users recognise and abide by the legal requirements associated with these rights.

- Users may download and print one copy of any publication from the public portal for the purpose of private study or research.

- You may not further distribute the material or use it for any profit-making activity or commercial gain

- You may freely distribute the URL identifying the publication in the public portal.

If the publication is distributed under the terms of Article 25fa of the Dutch Copyright Act, indicated by the "Taverne" license above, please follow below link for the End User Agreement:

www.tue.nl/taverne

Take down policy

If you believe that this document breaches copyright please contact us at:

openaccess@tue.nl

providing details and we will investigate your claim. 


\section{Beta}

Research School for Operations

Management and Logistics

Destocking, the Bullwhip Effect, and the Credit Crisis:

Empirical Modeling of Supply Chain Dynamics

Maximiliano Udenio, Jan C. Fransoo, and Robert Peels

Beta Working Paper series 438

\begin{tabular}{|rl|}
\hline BETA publicatie & WP 438 (working \\
paper) \\
ISBN & \\
ISSN & \\
NUR & 804 \\
Eindhoven & November 2013 \\
\hline
\end{tabular}




\title{
Destocking, the Bullwhip Effect, and the Credit Crisis: Empirical Modeling of Supply Chain Dynamics
}

\author{
Maximiliano Udenio ${ }^{1}$, Jan C. Fransoo ${ }^{1}$, and Robert Peels ${ }^{2}$ \\ ${ }^{1}$ School of Industrial Engineering, Eindhoven University of Technology, The Netherlands \\ ${ }^{2}$ Flostock, Eindhoven, The Netherlands
}

\begin{abstract}
In this paper we analyze the strong sales dip observed in the manufacturing industry at the end of 2008, following the bankruptcy of Lehman Brothers and the subsequent collapse of the financial world. We suggest that firms' desire to retain liquidity during these times prompted a reaction characterized by the reduction of working capital, which materialized as a synchronized reduction in target inventory levels across industries. We hypothesize that such a reaction effectively acted as an endogenous shock to supply chains, ultimately resulting in the demand dynamics observed. To test this proposition we develop a system dynamics model that explicitly takes into account structural, operational, and behavioral parameters of supply chains aggregated at an echelon level. We calibrate the model for use in 4 different business units of a major chemical company in the Netherlands, all situated 4 to 5 levels upstream from consumer demands in their respective supply chains. We show that the model gives both a very good historical fit and a prediction of the sales developments during the period following the Lehman collapse. We test the model's robustness to behavioral parameter estimation errors through sensitivity analysis, and the de-stocking hypothesis against an alternative model. Finally, we observe that the empirical data is aligned with experimental observations regarding human behavioral mechanisms concerning target adjustment times.
\end{abstract}

Keywords: System Dynamics; Bullwhip effect; Supply chain coordination; Behavioral decision making in supply chain planning 


\section{Introduction}

The world economy experienced a sudden, severe and synchronized collapse in late 2008. The magnitude of the drop in global trade was the largest since World War II, it was the steepest in recorded history, and it was synchronized: all 104 nations where data is collected by the WTO experienced a drop in imports and exports during the second half of the year (Baldwin 2009). Following the public collapse of the financial system (starting with the Lehman Brothers bankruptcy in September 2008), firms all over the world observed substantial demand disruptions; sales plummeted across the board, and panic spread. While many consumer markets remained relatively stable (exceptions being consumer durables and capital goods), the manufacturing sector observed almost instantaneous demand drops (Dooley et al. 2010).

In crises such as these, managers are pressured to improve the financial position of the company at the same time that demand levels are dropping dramatically. This typically leads to strategic decisions such as reducing inventories (to reduce the level of working capital), downsizing (to reduce operational expenses), and closing manufacturing facilities (to reduce fixed assets). These decisions, however, have substantial operational consequences when demand increases at a later stage: the reduction of inventory levels, workforce, and manufacturing facilities are decisions that require significant time to be reversed. If the situation that triggered such decisions is temporary and demand recovers faster than the speed at which firms can react, lost sales and general problems with inventory management will appear. Knowledge about the underlying dynamics behind the demand slump is therefore needed to avoid costly mistakes.

These underlying operational dynamics are a focus of extensive study as part of the systemsthinking approach introduced by Forrester (1958). This approach centers on the use of System Dynamics as the preferred methodology to replicate and understand the dynamic behavior of complex systems. System Dynamics models explicitly simulate the behavior of individual components pursuing local results, and exploit the structure of the system to model the interactions between these components. In doing so, System Dynamics allows the modeler to decouple endogenous, exogenous, and structural effects.

With regards to supply chain dynamics, observations are generally made that (a) production variance tends to be greater than demand variance, and (b) that this difference increases the further upstream a firm is. This has the effect of greatly amplifying demand fluctuations through a supply chain, and has been named 'the bullwhip effect' (Lee et al. 1997a). Analytical studies 
quantify this effect (Chen et al. 2000); empirical studies show evidence of its existence at a firm level (Metters 1997, Fransoo and Wouters 2000, Bray and Mendelson 2012); and a substantial experimental body of work investigates its causes and possible solutions (Sterman 1989, Croson and Donohue 2006). Empirical evidence of the bullwhip effect at higher aggregation levels is, however, ambiguous: conclusive evidence of neither variance amplification nor production smoothing has been found in public data (see Cachon et al. 2007, for a study based on U.S data). This apparent incompatibility between the predictions of the theory -supported by experimentation-, and high-level observations is, however, explained by the effects of data aggregation. Chen and Lee (2012) prove that both product aggregation (whereby multiple items are grouped into categories), and temporal aggregation (whereby information is grouped into quarters) mask the magnitude of the bullwhip effect.

In this paper, we argue that firms reacted to the 2008 financial crisis by reducing their working capital targets and -because it was global and synchronized- this reaction introduced a significant shock in the world's supply chains, essentially creating an inventory-driven bullwhip effect. To test our hypothesis, we adopt supply chain modeling, experimentation, and validation methods based on theory from the experimental work by Sterman (1989) and Croson and Donohue (2006), originally focused on the appearance of the bullwhip effect following demand shocks in a laboratory setting. We develop 4 different supply chain models for a major chemical company in the Netherlands and validate them with demand data from the crisis period. In terms of methodology, our work distinguishes itself from previous studies on inventory dynamics by using extensive empirical data, framing the Lehman Brothers collapse as a natural experiment. We specifically distinguish between the direct estimation of the operational model parameters such as lead times, and the econometric fitting of behavioral parameters such as stock adjustment times. In terms of theory, we model aggregates of companies at a particular level of the supply chain in a particular region rather than individual decision makers (as is common in experiments) or firms (as is common in much of the system dynamics literature in supply chain management). The crisis time-frame, through the resulting synchronization in managerial objectives, gives us the opportunity to link aggregate and individual human behaviors.

Our results show that demand drops in the respective end markets were not severe enough to explain -by themselves- the wild dynamics observed upstream. Moreover, we show that the combination of declining end-markets and the appearance of a synchronized inventory shock successfully account for a significant portion of the observed long and short term dynamics. In 
this view, exogenous end-markets drive the overall long-term evolution of sales, while endogenous behavior (such as the inventory decisions taken as a consequence of the crisis) primarily impacts the short term dynamics.

The contribution of this paper is thus threefold: (1) We identify the 2008 financial crisis as a natural experiment that -with the introduction of a synchronized inventory shock- effectively controls for the masking effects of aggregation. This allows for the usage of a system dynamics framework based on the bullwhip effect literature whereupon we model aggregate echelons. (2) We introduce a de-stocking hypothesis capable of explaining the demand evolution observed by upstream companies following the bankruptcy of Lehman Brothers. (3) We identify the importance of both consumer end-markets, and ordering behavior in the evolution of demand patterns through time. By explicitly modeling separate structural, operational, and behavioral parameters, this study quantifies their contribution to the observed transient behavior and allows for a comparison with results obtained from experimental studies on individual human decision making.

The remainder of this paper is organized as follows: In Section 2 we introduce the historical views of inventories as seen in the economics literature, we identify the challenges inherent in the study of inventories as part of aggregate models, and develop our de-stocking hypothesis. Section 3 introduces the methodology and model formulation, extending prior experimental work and framing it in the crisis time-period by explicitly modeling behavioral managerial decisions in the form of a reduction of inventory targets. In Section 4, the echelon model is used to model four different supply chains, we use empirical data to calibrate and validate the models, and develop forecasts for these supply chains. We then formulate an alternative model -sans the de-stocking hypothesis- to study the appropriateness of this hypothesis. We conclude in section 5 with a series of managerial insights.

\section{Background and Hypothesis Development}

When looking at the link between inventories and macro economic developments, Blinder and Maccini (1991) point out that interest in inventory behavior seems to follow cycles, not unlike the economy we attempt to explain. Indeed, we observe that research on the role of inventories in the economy peaks throughout history following extraordinary economic happenings such as the post-war period, the late seventies oil crisis, and -relevant to current developments- the 
financial crisis of 2008 .

We refer the reader to Fitzgerald (1997) and Blinder and Maccini (1991) for comprehensive reviews of over 50 years of discussions on inventory theory in the economics discipline. In his work, Fitzgerald (1997) identifies inconsistencies between theory and data, and the subsequent attempts of researchers to eliminate these discrepancies from their models. Blinder and Maccini (1991) summarize the opposing views of micro and macro economists with regards to the role of inventories: the former discipline sees them as a stabilizing factor, whereas the latter sees them as a de-stabilizing one. Despite these fundamental disagreements, Feldstein and Auerbach (1976) point out, inventory fluctuations have long been recognized as a major endogenous force in American business cycles. In their experience, irrespective of the conceptual contradictions between contemporary models and the real-life processes behind them, most studies of inventory behavior note that about 75 percent of the cyclical downturn in gross national product (from peak to trough) can be accounted for by the reduction of business inventories. Recognizing these conceptual difficulties, Lovell (1994) reflects upon the inherent challenge of trying to reconcile these views. He poses a series of questions that -for all the body of research availableremain open to this day: "(...) Do firms actually attempt to smooth production? Is an empirical analysis of industry-level data enough? Is it necessary to analyze firm-level data in order to explain these effects?". These questions read as a research agenda on the mechanisms behind empirical observations on both macro and micro levels, recognizing, amongst other issues, the potential masking effects of aggregate data. In the operations management literature, inventory theory is often developed in a stylized manner; with strong assumptions that favor mathematical tractability over the inclusion of the myriad factors that are present in real life. The objective of these simplifications is to develop managerial insights that are both rigorous, and useful in the real world. In an exploratory study, Rumyantsev and Netessine (2007) find evidence that many insights from classical inventory models survive aggregation and do, in fact, hold up when analyzing empirical data.

The dynamics that stem from the interactions of subsequent echelons along a supply chain have been extensively studied in the operations management literature. The fact that relatively small shocks can introduce severe instabilities in entire systems was shown by Forrester (1958), and is a central idea behind the bullwhip effect. The bullwhip effect has long been analytically and experimentally understood, and its effects and causes have sparked a great amount of research 
that has delivered valuable managerial insights (Sterman 1989, Lee et al. 1997b, Croson and Donohue 2006). However,even though the bullwhip effect itself is significant at the firm level (Metters 1997, Fransoo and Wouters 2000, Bray and Mendelson 2012), attempts to empirically quantify the effect at higher aggregation levels have not been successful: studies have failed to prove it statistically significant at an industry level (Cachon et al. 2007, Bu et al. 2011). The lack of clear empirical evidence is attributed to the influence of factors present in government statistics such as their high level of aggregation (Chen and Lee 2010), and seasonal adjustment (Gorman and Brannon 2000). Furthermore, as Rumyantsev and Netessine (2007) point out, extending many structural properties from single-product, single-echelon models to higher aggregation levels also requires the assumption that products be homogeneous and their inventory control be synchronized.

With this in mind, the financial crisis of 2008 allows us to study empirical data in a different way. Following the bankruptcy of Lehman Brothers on September 2008, the financial world found itself in turmoil; credit dried up almost instantly and many companies in the world shifted their financial priorities according to the "cash is king" motto: liquidity became essential. Freeing up cash in the short term through inventory divestment is one strategy that can be followed by companies in times of distress (Sudarsanam and Lai 2001). In a recent work, Pesch and Hoberg (2013) conduct an empirical study that shows that firms in financial distress reduce their inventories as part of their turnaround strategy: $70 \%$ of the firms in their sample reduce their inventories, with a median reduction of $9.4 \%$ of all inventories. We hypothesize that firms all over the world reacted to the financial collapse by significantly reducing their inventory targets. This, combined with the extraordinary synchronization observed during the the period (Alessandria et al. 2010) and the ever increasing influence of supply chain dynamics in the global economy (Escaith et al. 2010), introduced a synchronized, endogenous, inventory shock that generated an inventory-driven bullwhip effect. Early studies following the financial crisis seem to confirm this view in the manufacturing sector (Dooley et al. 2010). Using the collapse as a natural experiment, we model supply chains at an aggregate-echelon level, use exogenous end market data to drive those models, and validate them with primary empirical data collected at a major dutch chemical company. 


\section{Theoretical Background and Model Structure}

In this section, we present our echelon model based upon Sterman's managerial decision making and supply chain models (Sterman 1989, 2000) and follow with an introduction to the de-stocking logic we use to model the hypothesized reaction to the credit crisis.

\subsection{Echelon model}

An echelon model consists of three sectors (see Figure 1): the forecasting and orders sector tracks the incoming customer orders, maintains the echelon sales forecast, and generates material orders. The production sector regulates inventories and production, and the delivery sector keeps track of customer deliveries and backlogs. The model assumes no lost sales, and is based on continuous time system dynamics simulations. There is no sequence of events as such; cause and effect relationships are modeled by differential equations (i.e., we model rates of change), and products are modeled as continuous flows (demand is an outflow, incoming orders an inflow). Because these echelon models are intrinsically linked to one another (deliveries from one echelon will become material receipts for the echelon immediately downstream in its supply chain), each of the parameters we define has a subscript $[n=(1, \ldots, N)]$ representing its place in the supply chain. We number echelons from downstream to upstream: the most downstream echelon being 1 and the most upstream N. In the case of diverging supply chains, where one echelon can potentially have several direct customers, we introduce a second number following a period, indicating the existence of other parallel echelons in the supply chain.

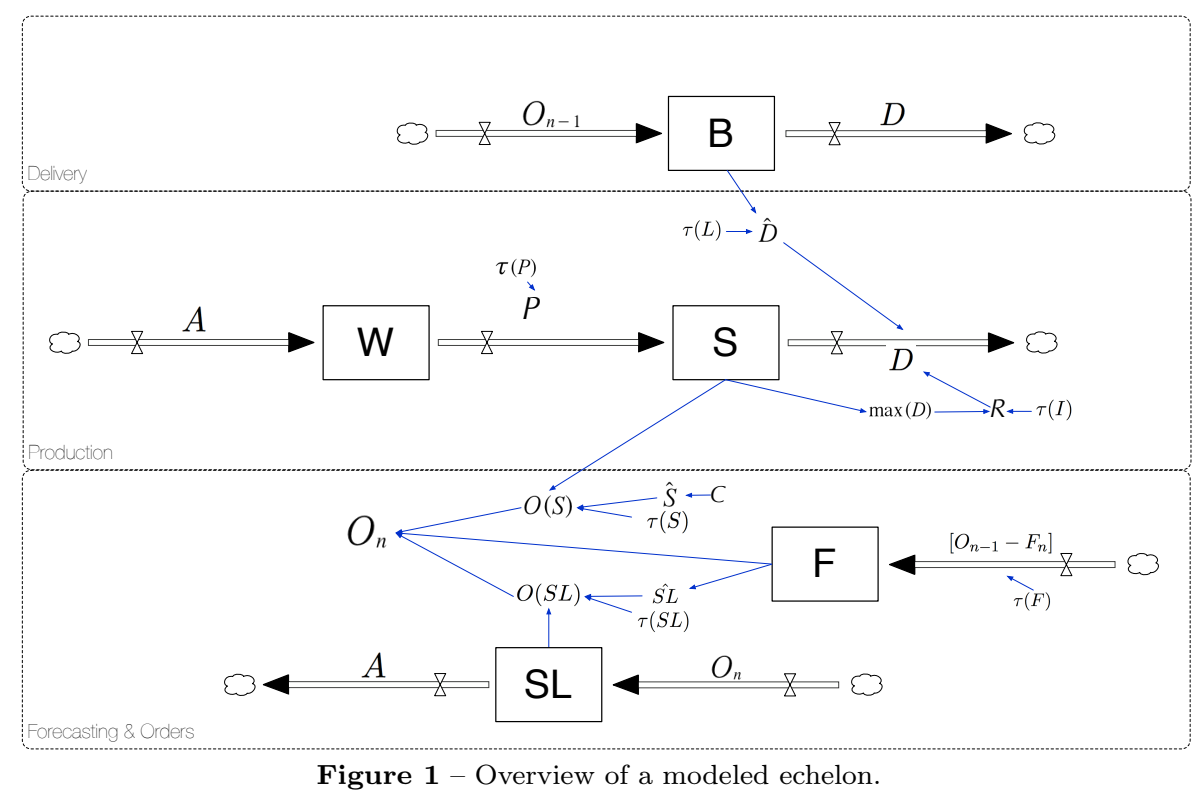




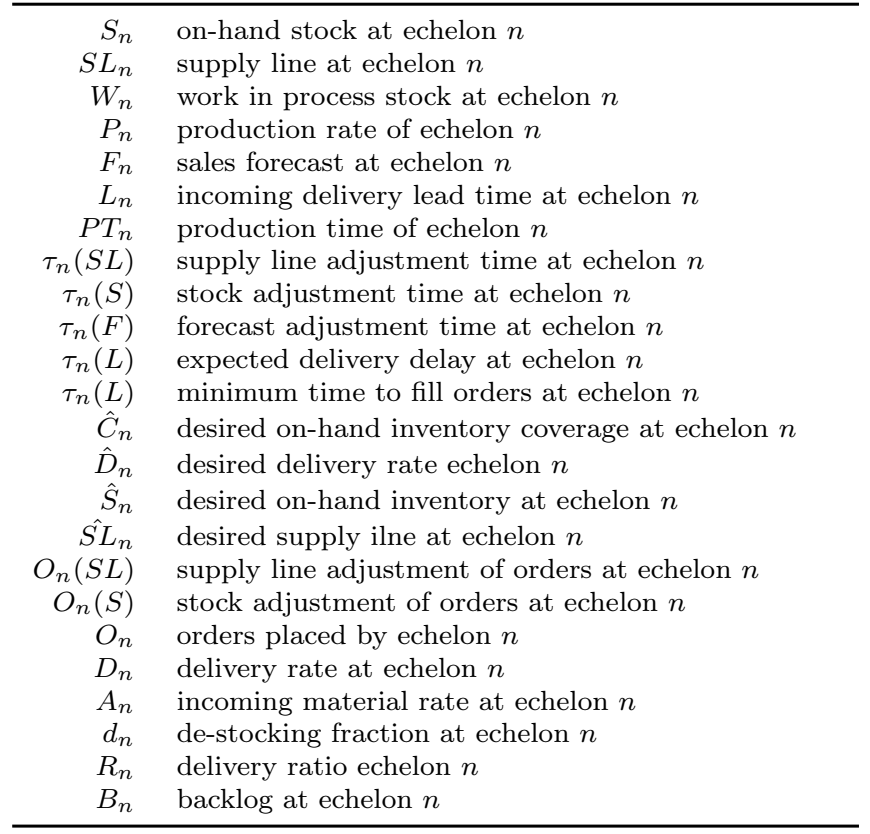

\section{$3.2 \quad$ Forecasting}

The forecasting sector maintains a sales forecast by accumulating the differences between the incoming customer demand $\left(O_{n-1}\right)$ and the previous forecast $\left(F_{n}\right)$. When demand exceeds the forecast it's updated upwards and vice-versa. To allow for a smoothing of the forecast, these differences are divided by the forecast adjustment time $\left(\tau_{n}(F)\right)$, indicating whether the whole difference or only a fraction is taken into account.

$$
\left(\frac{d}{d t}\right) F_{n}=\frac{O_{n-1}-F_{n}}{\tau_{n}(F)} .
$$

\subsection{Production}

The production sector models the flow of material through the echelon. The incoming material rate $\left(A_{n}\right)$ is equal to the delivery rate of the immediately upstream echelon $\left(D_{n+1}\right)$,

$$
A_{n}=D_{n+1} .
$$

The supply line is the cumulative difference between orders placed and orders received,

$$
\left(\frac{d}{d t}\right) S L_{n}=O_{n}-A_{n} .
$$

Incoming material is stored as work in process $\left(W_{n}\right)$. In the interest of simplicity we do not model any production release rule. Thus, the work in process stock is not used strategically or as a control variable: all incoming material is committed to production, and the production rate is modeled by applying a fixed delay (equal to the production time $P T_{n}$ ) to the order arrival 
rate. System dynamics modeling allows for the introduction of this discrete step in the model, which approximates the real production process,

$$
P_{n}=D E L A Y\left(A_{n}, P T_{n}\right) .
$$

Equation 4 assumes a production model where the manufacturing time is independent of the utilization rate, it also implicitly assumes that there are no capacity limitations for production (the model can be straightforwardly extended to include capacity limitations).

On -hand inventory $\left(S_{n}\right)$ depends on the delivery rate $\left(D_{n}\right)$ and the production rate $\left(P_{n}\right)$,

$$
\left(\frac{d}{d t}\right) S_{n}=P_{n}-D_{n} .
$$

Material orders are based on an anchor and adjustment heuristic (Tversky and Kahneman 1974): the sales forecast acts as the anchor, with the adjustment stemming from the difference between actual and target stock (and supply pipeline) levels.

To calculate the target stock, we start with the desired on hand inventory coverage measured in time units $\left(\hat{C}_{n}\right)$. When this is multiplied by the sales forecast, we obtain the desired on hand stock $\left(\hat{S}_{n}\right)$ in units of product.

$$
\hat{S}_{n}=\hat{C}_{n} F_{n}
$$

Analogously, there is a supply line level $\left(\hat{S L_{n}}\right)$ consisting of the multiplication of the lag (lead time) and the forecasted volumes,

$$
\hat{S L_{n}}=F_{n}\left(L_{n}\right) .
$$

\subsection{Orders}

Once we have calculated the desired levels of on-hand and supply line inventories, we generate adjustment orders with the purpose of closing the gap between the actual values of these inventories, and their desired (target) levels. The inventory adjustment time $\left(\tau_{n}(S)\right)$ and supply line adjustment time $\left(\tau_{n}(S L)\right)$ represent the time allowed for these quantities to reach the desired levels. These adjustment times model the behavioral aspect of the order generation. Short times imply a nervous buying behavior whereas a long adjusting time is equivalent to a smooth ordering strategy. We define the stock adjustment orders $\left(O_{n}(S)\right)$ and supply line adjustment orders $\left(O_{n}(S L)\right)$ as,

$$
\begin{gathered}
O_{n}(S)=\frac{\hat{S}_{n}-S_{n}}{\tau_{n}(S)}, \\
O_{n}(S L)=\frac{\hat{S L_{n}-S L_{n}}}{\tau_{n}(S L)} .
\end{gathered}
$$


Equations 8 and 9 calculate the difference between desired and actual values and spread these in equal parts over the amount of periods specified by the adjustment times. Finally, generated orders $\left(O_{n}\right)$ are calculated as,

$$
O_{n}=\max \left\{0, F_{n}+O_{n}(S)+O_{n}(S L)\right\} .
$$

\subsection{Delivery}

A backlog is used to keep track of orders. The backlog is calculated as the cumulative difference between the incoming customer order rate $O_{n-1}$ and actual delivery rate $\left(D_{n}\right) . O_{0}$, the demand observed by the echelon closest to the end market, is the only exogenous input to the model1,

$$
\left(\frac{d}{d t}\right) B_{n}=O_{n-1}-D_{n} .
$$

The order delivery rate $\left(D_{n}\right)$ is the rate of product that is actually shipped out in response to the incoming customer orders. To calculate this, we first define the desired delivery rate $(\hat{D})$, which is equal to the current backlog divided by the expected delivery delay $\left(\tau_{n}(L)\right)$,

$$
\hat{D}_{n}=\frac{B_{n}}{\tau_{n}(L)} .
$$

The maximum delivery rate $\left(\max (D)_{n}\right)$ per period depends on the ability of firm to physically prepare the products for shipment, modeled as the minimum time to fill orders $\left(\tau_{n}(I)\right)$,

$$
\max (D)_{n}=\frac{S_{n}}{\tau_{n}(I)} .
$$

We calculate the delivery ratio $\left(R_{n}\right)$ as the proportion of outstanding orders that can be shipped from stock,

$$
R_{n}=\min \left\{1, \frac{\max (D)_{n}}{\hat{D}_{n}}\right\}
$$

Finally, the actual order fulfillment rate is equal to the desired delivery rate multiplied by the delivery ratio,

$$
D_{n}=\hat{D}_{n} R_{n}
$$

Alternatively, we can combine equations 12 to 15 and define the order fulfillment rate as:

$$
D_{n}=\min \left\{\frac{B_{n}}{\tau_{n}(L)}, \frac{S_{n}}{\tau_{n}(I)}\right\} .
$$

\subsection{Modeling de-stocking decisions}

We model de-stocking decisions by decreasing the desired inventory coverage $\left(\hat{C_{n}}\right)$ of an echelon $n$ at time $T$ by a fraction $d_{n}$ (with $\left.0 \leqslant d_{n}<1\right)$. 
Thus, we can define $\hat{C}_{n}$ as:

$$
\hat{C}_{n}= \begin{cases}\hat{C}_{n} & \text { if } t<T \\ \hat{C}_{n}\left(1-d_{n}\right) & \text { if } t \geqslant T,\end{cases}
$$

Where $C_{n}$ is the desired stock coverage in "normal" (non-crisis) situations. It is important to note that de-stocking is a decision to lower target stock levels that are measured in time units. It is not a decision to reduce its absolute value, nor does it imply the destruction or writing-off of inventory. In this way, we separate explicit decisions to lower inventory targets from the implicit reductions that come from a decrease in sales.

\section{External Validation and Forecasting}

In this section, we use the echelon model as a building block to construct, calibrate, and validate 4 different supply chain models based upon data collected at our research company.

The methodology presented thus far concerns the modeling of a single echelon in a supply chain: the input to an echelon model is a customer order and its output is an order placed to a supplier. To model a supply chain, we link echelon models according to the customer/supplier relationships defined by its structure (e.g, number of echelons, linear, divergent) and parameterize the individual echelons. Each of the echelon models is defined by 7 parameters that can be divided into two different subsets - observable and behavioral. Observable parameters describe the physical structure or other measurable phenomena (lead times, desired stock coverage, and production times). Behavioral parameters define relationships between internal variables product of explicit or implicit managerial decisions (stock adjustment time, supply line adjustment time, forecast adjustment time, and changes in inventory policies) and therefore need to be estimated through a process of calibration. We explain the model set-up and data collection in $\S 4.1$. Then, we define the structure of the modeled supply chains and their observable parameters in $\S 4.2$, and the calibration of behavioral parameters in $\S 4.3$. Finally, we study the historical fit of the model in $\S 4.4$, and analyze an alternative model — without the de-stocking hypothesis, in $\S 4.5$.

\subsection{Model set-up and data collection}

Two distinct flows appear when we link individual echelon models to form a supply chain model: an information flow that travels upstream (orders), and a material flow that travels downstream 
(deliveries). The information flow of any supply chain originates at the sales point of a finished product, i.e., its end-market. Thus, the demand information observed by an upstream firm is a function of the original signal, generated by the end-market, and transformed -throughout its flow upstream- by the subsequent echelons of the particular supply chain (in the case of divergent supply chains, the combination of end-market signals). We use the 2008 credit crisis as a natural experiment because it allows us to link these end-market signals to the corresponding upstream demand: the synchronization observed during the period effectively controls for the smoothing effects of aggregation. Explicitly, we assume that (a) firms at a given echelon share the same structure, (b) firms at a given echelon share the same behavior during this time frame, and (c) the information distortion that is observed in the passage of demand information upstream -from its origin in the end-market- corresponds to locally rational policies at each stage of the supply chain (i.e., no demand information is arbitrarily created or discarded by intermediate echelons). We base this approach upon the observation that empirical data shows that during the credit crisis turning points in sales and inventories were indeed aligned by tiers (retail, wholesale, and manufacturing) (Dooley et al. 2010), suggesting that companies along a single echelon exhibited a synchronized behavior.

Conceptually, we model echelons that represent individual tiers: a group of competing companies providing the same product to the same supply chain. This follows what Sprague and Wacker (1996) define as the modeling with a "disaggregation by stages along the inventory stream". They point out that management practice generalizations made in this way recognize the impact of the management of inventory as it progresses through the stages. In particular, we model 4 different supply chains that belong to a dutch chemical company. As a reference, the different supply chains belong to four different business units that are situated 4-5 echelons upstream from retail demand. The upstream products of these supply chains are different resins, thermoplastics, and polymers. The end-markets where these are found are shown in Table 2

We use monthly, EU27 data available from Eurostat as a proxy for the demand for each of the end-markets for the period of Jan 2005-Aug 2009. The series used are: Construction index, automobile registrations, household goods retail index, and production indexes for: food products (C10), paper and paper products (C17), glass and glass products (C231), basic metal and metal products (C24), and motor vehicles (C291). All data is normalized with the average of $2007=100$. The work at each of the four sites of the company began with a kickoff meeting with management where the objectives and scope of the study were explained and defined. Fol- 
Table 2 - Summary of end-markets served by the 4 modeled supply chains

\begin{tabular}{|c|c|}
\hline Supply Chain & End Markets \\
\hline Supply Chain 1 (resins a) & $\begin{array}{l}\text { Residential and commercial construction; } \\
\text { Residential and commercial repair \& maintenance. }\end{array}$ \\
\hline Supply Chain 2 (resins b) & $\begin{array}{l}\text { Residential and commercial construction; } \\
\text { Residential and commercial repair \& maintenance; } \\
\text { Furniture sales. }\end{array}$ \\
\hline Supply Chain 3 (polymers) & Automotive sales. \\
\hline Supply Chain 4 (thermoplastics) & $\begin{array}{l}\text { Automotive manufacturing; Glass panel manufacturing; } \\
\text { Metal manufacturing; Food manufacturing; } \\
\text { Paper and pulp manufacturing; } \\
\text { Residential and commercial construction. }\end{array}$ \\
\hline
\end{tabular}

lowing these, interviews were conducted with employees to formalize data collection procedures. The structure of the supply chain model and the parameterization of observable parameters is based on input from these employees, complemented with information obtained from players distributed along the supply chain. The modeling work was performed on-site, which allowed for additional ad-hoc interviews and further familiarization with the particulars of each individual supply chain.

\subsection{Structure and observable parameters}

The number of echelons, structure, and end markets of each of the 4 supply chains are all different and can be seen in Figure 2. The supply chains in this study consist mainly of chemical firms upstream and make-to-stock component suppliers downstream. For this study, we consider our research site to be the upstream-most boundary of each supply chain. The parameterization of the observable parameters per echelon is shown in Table 3.

Table 3 - Observable Supply Chain parameters per echelon

\begin{tabular}{|c|c|c|c|c|c|c|c|c|c|c|c|c|c|c|c|}
\hline \multirow[t]{2}{*}{ Supply Chain 1} & \multirow{2}{*}{$\hat{C}$} & \multirow[b]{2}{*}{$L_{n}$} & \multirow[b]{2}{*}{$P T_{n}$} & \multicolumn{4}{|c|}{ Supply Chain 2} & \multicolumn{4}{|c|}{ Supply Chain 3} & \multicolumn{4}{|c|}{ Supply Chain 4} \\
\hline & & & & & $\hat{C}$ & $L_{n}$ & $P T_{n}$ & & $\hat{C}$ & $L_{n}$ & $P T_{n}$ & & $\hat{C}$ & $L_{n}$ & $P T_{n}$ \\
\hline 1.1 & 5 & 10 & 1 & 1.1 & 8 & 4 & 1 & 1 & 4 & 3 & 1.5 & 1 & 8 & 0.25 & 2 \\
\hline 1.2 & 5 & 10 & 1 & 1.2 & 4 & 4 & 1 & 2 & 2 & 1 & 1 & 2 & 14 & 0.25 & 5 \\
\hline 2 & 8 & 2 & 1 & 1.3 & 4 & 4 & 1 & 3 & 1.5 & 2 & 1 & 3 & 10 & 0.25 & 4 \\
\hline 3 & 8 & 2 & 1 & 2.1 & 8 & 4 & 1 & 4 & 1 & 2 & 1 & 4 & 8 & 0.25 & 1 \\
\hline \multirow[t]{3}{*}{4} & 4 & 2 & 1 & 3 & 8 & 0.25 & 1 & 5 & 2 & 2 & 1 & & & & \\
\hline & & & & 4 & 3 & 0.25 & 1 & & & & & & & & \\
\hline & & & & 5 & 2 & 0.25 & 1 & & & & & & & & \\
\hline destocking & 0.15 & & & & 0.25 & & & & 0.2 & & & & 0.1 & & \\
\hline
\end{tabular}

In an attempt to simplify the models, we assume deterministic lead times and the availability of resources such that order preparation does not introduce significant lags. Thus, the expected delivery delay $\left(\tau_{n}(L)\right)$ is equal to its own delivery lead time $\left(L_{n-1}\right)$, and the minimum time to fill 


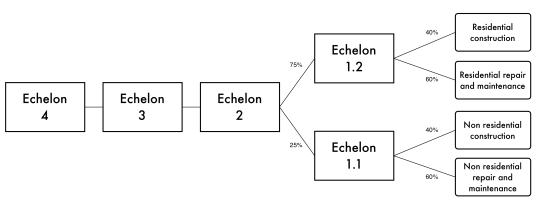

(a) Supply chain 1 .

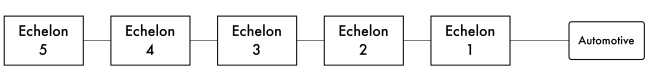

(c) Supply chain 3 .

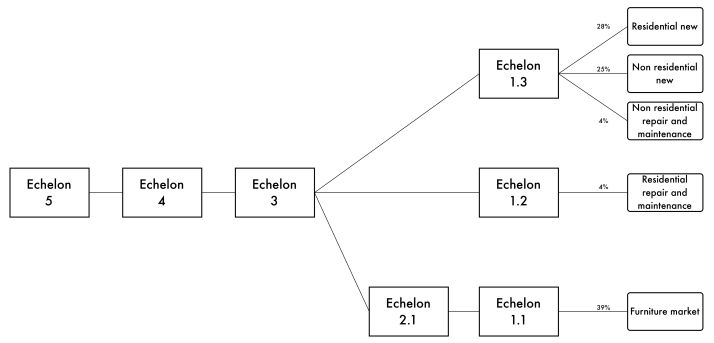

(b) Supply chain 2 .

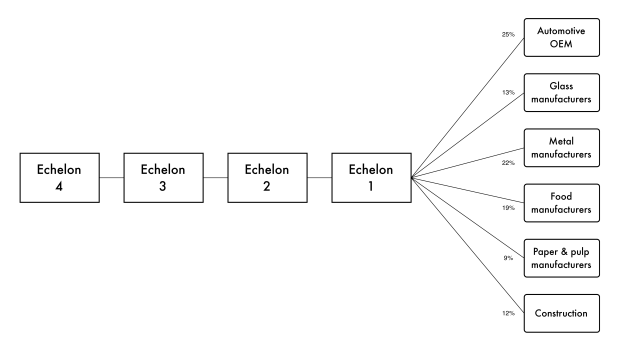

(d) Supply chain 4 .

Figure 2 - Supply chain structures

orders $\left(\tau_{n}(I)\right)$ is equal to 1 . Due to the absence of disaggregated data, the lead time is defined as the time between placing an order and its receipt (i.e., it encompasses both the informational and physical components of the delay). We make two assumptions regarding the boundary conditions: (1) orders placed by the uppermost echelon in a supply chain are always served by a supplier with infinite stock, and (2) downstream demand is exogenous and is composed of the individual demand signals of the end markets that require the materials produced upstream.

With the structure and observable parameters estimated for each of the supply chain models, we proceed with the analysis of the de-stocking decisions and the estimation of behavioral parameters through calibration.

\subsection{Model calibration and behavioral parameters}

Oliva (2003) defines model calibration as the process of estimating parameters to obtain a match between modeled and observed behavior and argues that it is, in itself, a stringent test of the validity of the model linking structure and behavior. Nevertheless, he points out that achieving a good historical fit is not enough to confirm the dynamic hypothesis behind the model; the model has to match the observed behavior for the right reasons. Partial model calibration, the process of estimating parameters within a subset of model parameters instead of the entire model parameter space, introduced by Homer (1983) is the preferred calibration strategy for system dynamics models because it "reduces the risk of the structure being forced into fitting the data, 
increases the efficiency of the estimation (estimators with smaller variances), and concentrates the differences between observed and simulated behavior in the piece of structure responsible for that behavior" (Oliva 2003). Unfortunately, we can't perform partial calibration for our supply chain models because we lack primary sales and inventory data at the intermediate levels, and it is not possible to map secondary empirical data to individual echelons. To overcome this, we perform a full model calibration and follow it with: $(i)$ a sanity check of the estimated parameters (is the model structure sound?) and (ii) the test of an alternative hypothesis (can we achieve the same behavior through a different structure?) to increase the confidence in our model.

We use the corresponding secondary EU27 end-market data as the input for each of the endmarkets in our models and primary sales data from our research company as a proxy for upstream demand. This assumption is reasonable all through the historical period used for the calibration (where no capacity shortages were observed). Due to the existence of only one exogenous time series, we use data from Jan 2005-Jul 2009 to calibrate the model, and use data from Jul 2009 onwards to validate the model. The calibration step is implemented within the simulation software; simulations are performed for each supply chain by generating model runs where all the observable parameters are fixed as established in $\S 4.2$, while the behavioral parameters are varied. The cumulative sum of square errors between the estimated demand and the historical sales data is calculated per run and the combination of parameters that minimizes this error is then chosen. Formally, the minimization corresponds to:

$$
\min _{\tau_{n}(F), \tau_{n}(S L), \tau_{n}(S)} \sum_{t=1}^{k}\left(O_{N-1}(t)-\tilde{D}_{N}(t)\right)^{2}
$$

Where $N$ is the most upstream echelon in the supply chain, and $\tilde{D}_{N}(t)$ is the historical sales data for time $t$ at echelon $N$ (our research company). In other words, we compare the orders generated by the modeled customers of our research site with the actual historical sales of said firm and search for the parameter values that minimize the error. The minimization is performed through a modified Powell-Brent algorithm (Brent 2002). For computational purposes and to reduce the search space, $\tau(S), \tau(S L)$, and $\tau(F)$ are estimated through their reciprocals, $\alpha_{S}, \alpha_{S L}$, and $\Theta$, and $\alpha_{S}, \alpha_{S L}, \Theta \in[0,1]$. Table 4 lists all the parameters estimated through calibration, including the $95 \%$ confidence intervals calculated through a sensitivity analysis. De-stocking fractions represent a non-observable parameter and were thus estimated through a combination of interviews and scenario analysis; experts identified a range of de-stocking fraction per supply 
chain, scenarios where then run with different values for $d$ (intervals of 0.05 ), and the best fit was chosen. All echelons in a supply chain are assumed to incur the same de-stocking behavior at the same time. This is motivated by: (a) recent literature suggesting synchronization during the crisis, (b) the availability of only upstream sales data as a calibrating time-series. The latter factor negates the additional information that could be gleaned from having individual de-stocking parameters: upstream sales are affected by the cumulative amount of inventory being taken out of the supply chain. These data are shown in Table 3 .

In all cases, the confidence bounds of the estimations for the uppermost echelon are lax: this is due to the data available for calibration being the historical sales of this echelon. None of the parameters in the model allow a firm to influence its own demand via strategic decisions. Thus, the uppermost echelon can either meet the demand or incur in destabilizing stock-outs. The confidence bounds represent the parameter space that allows for the former. Similarly, the amount of parameters being estimated from a single time series (between 12 and 21, depending on the supply chain) explain the size of the confidence intervals of the supply line adjustment time.

A parameter estimated to be $\infty$ corresponds to a parameter that is not taken into account in the ordering heuristic. We observe that, in accordance with the behavioral literature (Sterman 1989), the gap between desired and actual supply lines is severely underestimated in the ordering decisions: both the means and medians of the supply line adjustment time $(\tau(S L))$ are larger than the respective values for both the stock, and forecast adjustment times (two-sample ttests on the means, Wilcoxon rank-sum tests for the medians, all $p \leq 0.1$ ). When comparing the latter two, we find that the mean forecast adjustment time is larger than the mean stock adjustment time $(p \leq 0.1)$. However, this difference is caused by extreme values in supply chain 2 , as there is no statistical difference between the medians of these parameters. This implies that firms use their forecasts as an anchor, and steer primarily on their inventories. We next compare the stock adjustment times between supply chain models to test for any inherent differences in the parameterizations. We find that the mean and median adjustment times of supply chain 4 are significantly larger than those of supply chain $2(p \leq 0.1)$. All other mean and median differences are non-significant. This suggests that while supply chain 4 is less responsive than supply chain 2 , the overall behavior, and the mechanisms, behind all the supply chain models is comparable. 
Table 4 - Estimated behavioral Supply Chain parameters

\begin{tabular}{cccccrcrrr}
\hline & $\tau(S)$ & \multicolumn{2}{c}{$95 \%$ CI } & $\tau(S L)$ & $95 \%$ CI & $\tau(F)$ & \multicolumn{2}{c}{$95 \%$ CI } \\
\hline Supply Chain 1 & & & & & & & & & \\
1.1 & $\mathbf{3 . 9 1}$ & 3.14 & 4.93 & $\mathbf{6 . 1 6}$ & 4.05 & 9.48 & $\mathbf{5 . 4 9}$ & 1.53 & 11.27 \\
1.2 & $\mathbf{8 . 7 0}$ & 6.13 & 15.60 & $\infty$ & 191.79 & $\infty$ & $\infty$ & 794.62 & $\infty$ \\
2 & $\mathbf{9 . 7 0}$ & 8.96 & 10.70 & $\infty$ & 25.65 & $\infty$ & $\mathbf{1 0 . 3 0}$ & 8.43 & 12.76 \\
3 & $\mathbf{1 4 . 0 8}$ & 13.17 & 15.12 & $\infty$ & 31.05 & $\infty$ & $\mathbf{1 7 . 5 6}$ & 15.54 & 19.93 \\
4 & $\mathbf{1 0 . 0 0}$ & 1.42 & $\infty$ & $\mathbf{1 0 0 . 0 0}$ & 1.42 & $\infty$ & $\mathbf{6 . 0 3}$ & 1.00 & 2194.05 \\
Supply Chain 2 & & & & & & & & & \\
1.1 & $\mathbf{4 . 1 5}$ & 3.31 & 5.25 & $\infty$ & 3.50 & $\infty$ & $\mathbf{3 . 9 1}$ & 1.00 & 9.85 \\
1.2 & $\mathbf{3 . 9 9}$ & 1.00 & $\infty$ & $\infty$ & 1.00 & $\infty$ & $\mathbf{4 . 3 1}$ & 1.00 & $\infty$ \\
1.3 & $\mathbf{4 . 5 4}$ & 3.09 & 6.95 & $\infty$ & 5.30 & $\infty$ & $\mathbf{1 2 8 2 . 9 8}$ & 27.33 & $\infty$ \\
2.1 & $\mathbf{3 . 3 3}$ & 1.18 & 5.19 & $\mathbf{1 . 0 0}$ & 1.00 & 1.76 & $\mathbf{4 . 6 0}$ & 2.37 & 7.38 \\
3 & $\mathbf{7 . 2 0}$ & 6.20 & 8.4 & $\mathbf{1 0 . 0 0}$ & 1.00 & $\infty$ & $\mathbf{9 8 3 . 4 0}$ & 157.60 & $\infty$ \\
4 & $\mathbf{2 3 . 1 1}$ & 17.30 & 32.31 & $\mathbf{3 3 3 3 . 3 3}$ & 1.00 & $\infty$ & $\mathbf{8 . 1 0}$ & 6.30 & 9.10 \\
5 & $\mathbf{1 0 . 0 0}$ & 1.00 & 102.63 & $\mathbf{1 0 . 0 0}$ & 1.00 & $\infty$ & $\mathbf{6 . 0 3}$ & 1.00 & 33.45 \\
Supply Chain 3 & & & & & & & & & \\
1 & $\mathbf{9 . 6 9}$ & 7.22 & 12.69 & $\infty$ & 7.22 & $\infty$ & $\mathbf{2 1 . 6 4}$ & 13.69 & 37.33 \\
2 & $\mathbf{6 . 4 1}$ & 4.20 & 8.97 & $\infty$ & 4.20 & $\infty$ & $\mathbf{1 6 . 9 8}$ & 9.85 & 30.67 \\
3 & $\mathbf{8 . 7 4}$ & 6.32 & 11.81 & $\infty$ & 6.32 & $\infty$ & $\mathbf{1 1 . 0 2}$ & 6.85 & 17.08 \\
4 & $\mathbf{1 3 . 9 0}$ & 10.02 & 17.53 & $\infty$ & 10.02 & $\infty$ & $\mathbf{9 . 5 8}$ & 6.61 & 13.51 \\
5 & $\mathbf{1 0 . 0 0}$ & 1.00 & $\infty$ & $\mathbf{1 0 0 . 0 0}$ & 1.00 & $\infty$ & $\mathbf{6 . 0 3}$ & 1.00 & $\infty$ \\
Supply Chain 4 & & & & & & & & & \\
1 & $\mathbf{1 0 . 1 8}$ & 7.13 & 14.07 & $\mathbf{3 1 . 1 0}$ & 7.13 & $\infty$ & $\infty$ & 90.49 & $\infty$ \\
2 & $\mathbf{9 . 3 5}$ & 7.00 & 12.63 & $\mathbf{3 3 . 0 3}$ & 7.00 & $\infty$ & $\mathbf{1 6 . 9 1}$ & 9.03 & 31.49 \\
3 & $\mathbf{1 3 . 7 6}$ & 10.21 & 18.94 & $\mathbf{2 2 1 5 . 2 7}$ & 10.21 & $\infty$ & $\mathbf{1 1 . 5 3}$ & 6.83 & 18.96 \\
4 & $\mathbf{1 6 . 8 8}$ & 1.00 & $\infty$ & $\mathbf{1 0 1 . 7 3}$ & 1.00 & $\infty$ & $\mathbf{1 0 . 0 0}$ & 1.00 & $\infty$ \\
\hline
\end{tabular}

\subsection{Historical fit and structural validity}

Following the calibration, we run the four supply chain models driven by the exogenous end market and the de-stocking hypothesis. In contrast to the calibration step, runs are now performed with published historical end market data complemented with scenarios based upon published forecasts, and expectations of the business intelligence groups for subsequent periods.

Figure 3 shows the model outputs against the seasonally corrected upstream demand realizations. The vertical axis represents the demand expressed in $\%$ of the average 2007 demand and the dotted vertical lines indicate the threshold between historical fit and forecast values. Table 5 shows the root mean squared error (RMSE), $R^{2}$, and Theil inequality statistics for the data series shown in the figure. These inequality statistics decompose the mean square error into three fractions representing: unequal means $\left(U_{m}\right)$, unequal variances $\left(U_{s}\right)$, and imperfect correlation $\left(U_{c}\right)$ (Theil 1966). A low $U_{m}$ indicates a strong correspondence between the modeled mean and the actual mean, and a low $U_{s}$ indicates a similar correspondence between variances. Therefore, low variance and means statistics indicate that the error is unsystematic, and therefore desirable (Oliva and Sterman 2001).

The models, driven by one exogenous data series (end customer demand), and one "crisis re- 
Table 5 - Historical fit statistics

\begin{tabular}{lccccc}
\hline & RMSE & $R^{2}$ & $U_{m}$ & $U_{s}$ & $U_{c}$ \\
\hline Supply chain 1 & $4.53 \%$ & 0.65 & 0.031 & 0.190 & 0.779 \\
Supply chain 2 & $8.11 \%$ & 0.68 & 0.065 & 0.041 & 0.893 \\
Supply chain 3 & $6.74 \%$ & 0.88 & 0.040 & 0.210 & 0.750 \\
Supply chain 4 & $11.48 \%$ & 0.75 & 0.000 & 0.079 & 0.921 \\
\hline
\end{tabular}

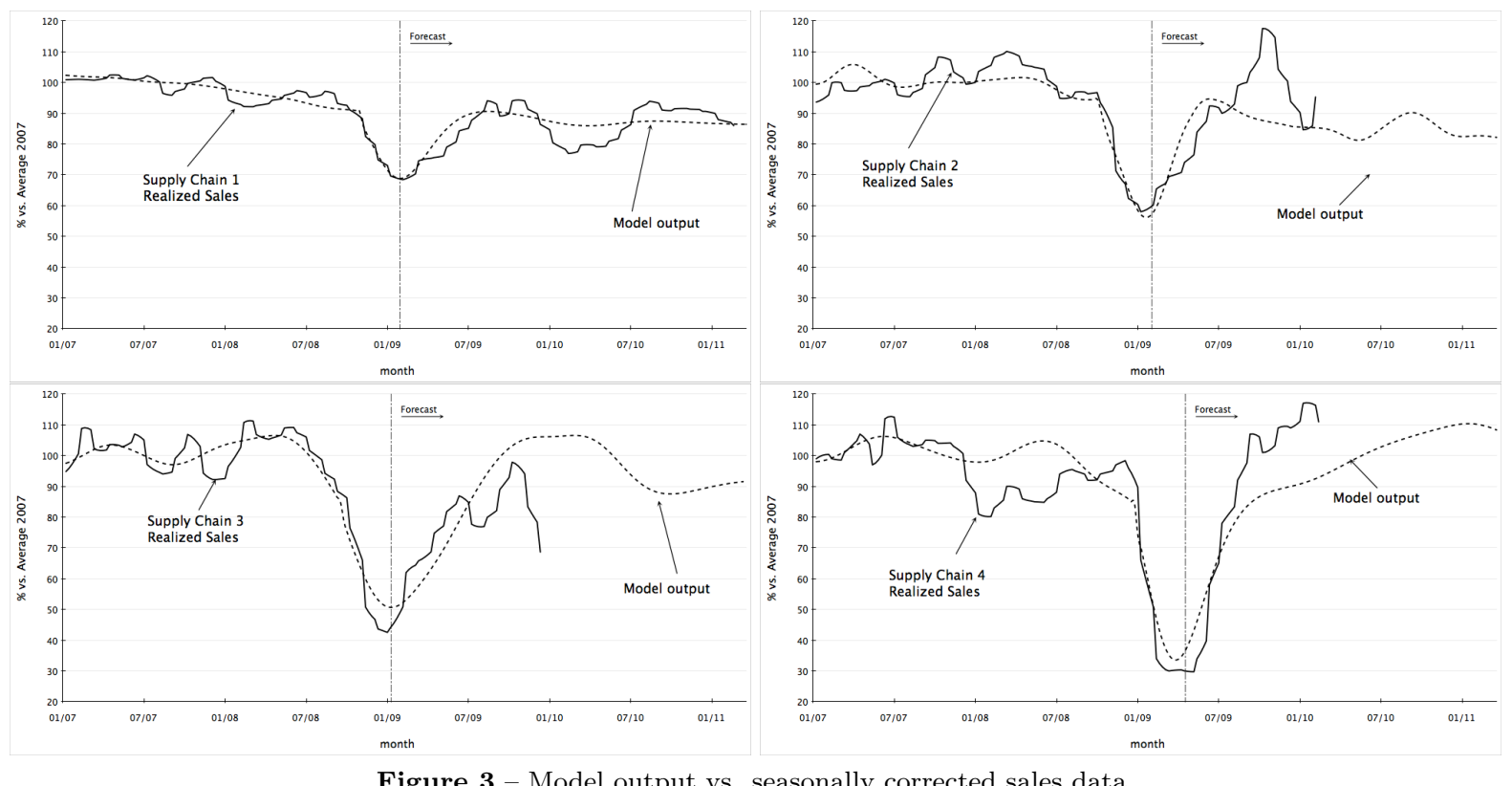

Figure 3 - Model output vs. seasonally corrected sales data.

sponse" policy (desired stock reductions in september 2008) shows a good tracking of the overall behavior of the system. However, a match between observed and simulated behavior is not in itself enough to accept the model and hypothesis. As Oliva (2003) explains, "There is a chance that a set of parameter values might be capable of replicating the observed behavior through a set of unrealistic formulations, and thus generate the right behavior for the wrong reasons". To test the validity of the model, we analyze what the estimated parameters say about its structure, and follow with the analysis of an alternative model to test whether the same behavior can be achieved through a different structure.

The system dynamics model presented in $\S 3$ is based on the anchor and adjustment heuristic for order generation (Tversky and Kahneman 1974). The same decision rule is used in a substantial amount of experimental work, were individual human behavior is analyzed in the context of the beer distribution game. Three of the most salient such studies are Sterman (1989), Croson et al. (Forthcoming), and Croson and Donohue (2006). In these experiments, students (and professionals) play the beer game (under different settings), and then the behavioral parameters are then fit through the use of regression analysis. From these publications, we can derive the 
estimate of the stock, supply line, and forecast adjustment times, and we see that in all cases the experimental studies conclude that subjects tend to under-estimate the supply line, and observe low reactiveness towards inventories and forecasts. The fact that these two phenomena can be observed in the behavioral parameters of our calibrated models increases our confidence on its structural validity.

\subsection{Alternative model}

The de-stocking hypothesis presented in this paper is motivated by a variety of results from the inventory management and economics literature. It has been shown that firms can convert assets into cash in the short-term (Sudarsanam and Lai 2001), and that lowering inventories is a common response to financial distress (Pesch and Hoberg 2013). Furthermore, studies focused on the mechanisms behind the recent 2008 financial crisis have reported on its extraordinary magnitude and synchronization (Alessandria et al. 2010). In line with this, anecdotal evidence points to decisions having been made to reduce working capital: formal and informal interviews with decision makers across the industry support this view.

However, the empirical validation of our hypothesis not possible: inventory targets are not explicitly reported, and we can't use actual inventories as a proxy for inventory targets during the time-frame of this study. The decision to reduce inventory targets triggers a shock that immediately affects orders, but its effect on inventory levels is substantially more complex: the combination of time delays and declining demand caused inventory levels to spike following the start of the crisis, further increasing the gap between target and actual inventory levels.

Therefore, to further test our model and -in particular- the de-stocking hypothesis driving it, we perform additional experiments to rule out alternative explanations. In Figure 4 we observe the model output of a calibrated alternative model without the de-stocking hypothesis. The alternative model differs from the original model only in that it does not allow for any destocking to be performed at any point in the supply chain, and its calibration follows the same procedure outlined in $\S 4.3$. Table 6 shows the fit statistics.

Table 6 - Alternative model fit statistics

\begin{tabular}{lccccc}
\hline & RMSE & $R^{2}$ & $U_{m}$ & $U_{s}$ & $U_{c}$ \\
\hline Supply chain 1 & $7.69 \%$ & 0.002 & 0.004 & 0.682 & 0.314 \\
Supply chain 2 & $11.96 \%$ & 0.259 & 0.007 & 0.260 & 0.733 \\
Supply chain 3 & $12.83 \%$ & 0.611 & 0.068 & 0.009 & 0.923 \\
Supply chain 4 & $15.96 \%$ & 0.577 & 0.011 & 0 & 0.988 \\
\hline
\end{tabular}



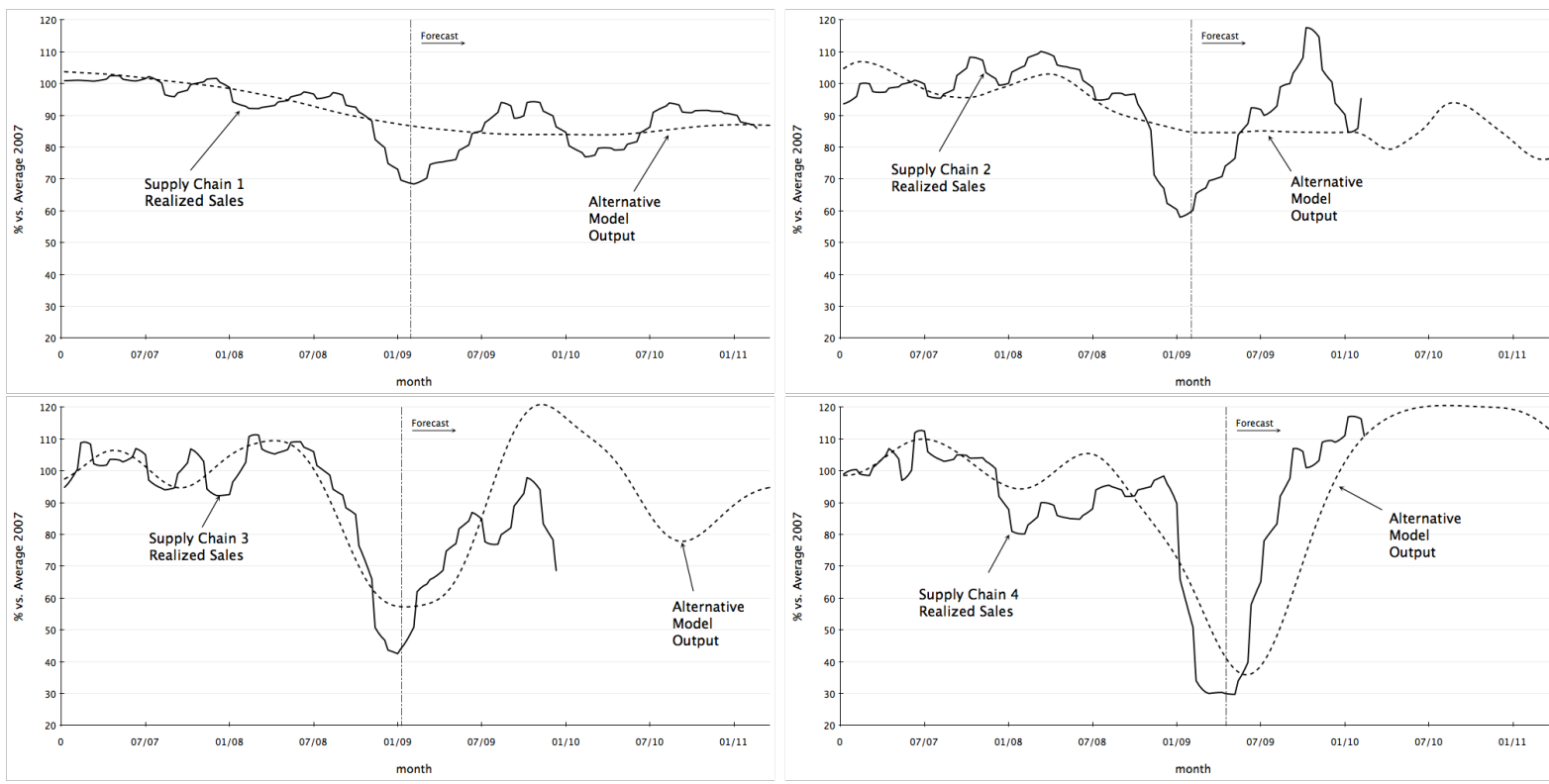

Figure 4 - Alternative model output.

Table 7 - Summary statistics for original and alternative models

\begin{tabular}{lccccc}
\hline Variable & Mean & St. Dev & 1st Quartile & Median & 3rd Quartile \\
\hline \multicolumn{5}{c}{ Original Model } \\
\hline$\tau(S)$ & 9.67 & 4.81 & 6.41 & 9.69 & 10.18 \\
$\tau(S L)$ & 7254.17 & 23152.01 & 31.10 & 100 & 101.73 \\
$\tau(F)$ & 360.80 & 1096.79 & 6.03 & 10.15 & 17.27 \\
RMSE & 7.72 & 2.91 & 5.64 & 7.43 & 9.80 \\
$R^{2}$ & 0.74 & 0.10 & 0.67 & 0.72 & 0.82 \\
\hline \multicolumn{5}{c}{ Alternative Model } \\
\hline$\tau(S)$ & 10.96 & 3.51 & 10 & 11 & 12.86 \\
$\tau(S L)$ & 38009.98 & 68070.23 & 17.55 & 72.72 & 89756.50 \\
$\tau(F)$ & 8.89 & 3.59 & 6.03 & 9.96 & 10.99 \\
RMSE & 12.11 & 3.41 & 9.83 & 12.40 & 14.40 \\
$R^{2}$ & 0.36 & 0.29 & 0.13 & 0.42 & 0.60 \\
\hline \multicolumn{7}{c}{}
\end{tabular}

We see that the alternative model adequately tracks the average, or long-term, demand variations but cannot explain the magnitude of the demand drops nor their timing. If we compare the alternative model runs with the original (de-stocking) model runs we can see that the end market sales drive the long-term evolution of upstream sales, while the short term dynamics are dominated by shocks. In Table 7 we present the summary statistics for the relevant variables of both models. We perform two-sample t-tests for the means and find that the alternative model has a significantly larger RMSE and a lower $R^{2}$ than the original model (all $p \leq 0.05$ ). Similarly, testing the effect on the medians (Wilcoxon rank-sum test) gives the same results $(p \leq 0.1$, and $p \leq 0.05$ respectively). 
Additionally, we test for differences in the estimated parameters: the means of the forecasting, and supply line adjustment times differ at the $p \leq 0.1$ level when comparing original and alternative models, but no such difference is found when testing for difference in the median values. This is consistent with the observation that abnormally large values of these parameters skew the average results. In general, we observe that all the calibrated models exhibit characteristics consistent with experimental findings: slow reaction speeds and an under-weighing of the supply line.

\section{Conclusions and Managerial Insights}

Behavioral dynamics in supply chains have been widely researched. Initial studies by Forrester (1958) analyzed data at the level of individual or series of companies. Following the work by Lee et al. (1997a), extensive analytical work has been conducted, and more recently, driven by the work by Sterman (1989) and Croson and Donohue (2005), focus has been on laboratory experimentation. On the empirical front, Cachon et al. (2007) does not find conclusive evidence for the existence of the bullwhip effect in aggregate empirical data. Chen and Lee (2010), through analytical work, argue that it is the aggregation of the data that plays an important role in hiding some of the effect, which is observed at a firm level (Bray and Mendelson 2012).

In this study, we use observations following the collapse of Lehman Brothers in the Fall of 2008 to develop a hypothesis regarding target level setting and investigate the explanatory power of behavioral dynamics. Our study observes demand at the level of an individual company, but takes into account the hypothesized dynamic decision making behavior at meso-level. With this, our study sets itself apart from previous studies, and not only builds upon the lines of research discussed above, but also on research in economics studying inventory cycles.

Our results show that the theoretical results of Sterman (1989) and Croson and Donohue (2005) together with an endogenous inventory shock, can explain the dynamic evolution of demand observed upstream in the periods following the start of the recent credit crisis. The endogenous replenishment process drives the evolution of demand throughout the supply chain, determined by structural characteristics of the supply chain (following Forrester (1958)) and the hypothesized human behavior (following Sterman (1989)). The empirical evidence presented shows that slow reaction speeds, and an apparent underestimation of the supply pipeline are prevalent at higher aggregation levels, suggesting that they go beyond being a phenomenon of individual 
decision-making biases. At this level, the supply line underestimation seems to be caused not from an incorrect estimation of target values, but as a combination of the inherent reaction time of firms and a decision rule that eschews the tracking of the supply line by instead steering on large amounts of on-hand inventory. This finding calls for further study on the ordering behavior of firms; if behavioral biases influence decision-making at the echelon level, how can -and should-firms overcome them?. Equally important: how do these behaviors change over time? In addition to this contribution to theory, we also demonstrate that these insights can be used operationally for demand predictions. We develop a prediction method by which final consumer demand, potentially four to five levels down the supply chain, is taken as the only exogenous information, and then the system dynamics models are used to propagate the demand upstream. Our results in four supply chains show a high level of forecast accuracy. While the exogenous demand at consumer level drives the overall demand evolution, short-term demand dynamics are mainly driven by endogenous ordering decisions in the supply chain and the de-stocking response to the crisis. To increase the confidence in our de-stocking hypothesis, we test the models in the absence of the inventory shock induced by the synchronized de-stocking, and find that while they show good tracking of the long term evolution, they cannot replicate the magnitude and timing of the observed upstream demand.

For managers, our results have implications at both the strategic and tactical levels of decision making. Tactically, for managers it is much more important to keep track of consumer demands, supported by an endogenous simulation of ordering behaviors to make demand forecasts, rather than relying exclusively on information obtained from one or two echelons downstream. These simulation-based forecasts can drive decisions on plant openings and closures, staffing decisions, and aggregate inventory strategies. Strategically, we show that the structure of the supply chain impacts the clockspeed at which the supply chain operates. In this sense, we provide a formal model to (a) analyze the effects of structural changes in the supply chain, and (b) be used as a decision-making tool in which endogenous behavioral changes form the basis of scenario-based forecasting.

By exploiting the synchronization of decisions in the period, in particular the decrease in target stock levels as a response to the crisis, we show that behavioral traits observed in individual decision-making experiments can account for a considerable part of the aggregate supply chain dynamics observed in this empirical study. This suggests that one of the preliminary experimental findings of Croson et al. (Forthcoming), in which participants appear to endogenously 
vary target inventory levels as a response to instabilities observed in their own supply chains, is supported by the empirical data. The next step in future research, both empirical and experimental, is to test whether endogenous mechanisms governing this behavior (de-stocking and hoarding) can be found.

\section{References}

Alessandria, George, Joseph P. Kaboski, Virgiliu Midrigan. 2010. The great trade collapse of 2008-09: An inventory adjustment? NBER Working Papers 16059, National Bureau of Economic Research, Inc.

Baldwin, R. 2009. The great trade collapse: Causes, Consequences and Prospects. Centre for Economic Policy Research.

Blinder, A.S., L.J. Maccini. 1991. Taking stock: A critical assessment of recent research on inventories. The journal of economic perspectives 5(1) 73-96.

Bray, Robert L., Haim Mendelson. 2012. Information transmission and the bullwhip effect: An empirical investigation. Management Science 58(5) 860-875.

Brent, R.P. 2002. Algorithms for minimization without derivatives. Dover Publications.

Bu, Xiang-zhi, Zheng-hua Zhou, Rong-fang Guo. 2011. An empirical study on bullwhip effect in the supply chain; based on the statistical data from manufacturing industry of china. Service Systems and Service Management (ICSSSM), 2011 8th International Conference on. 1-6.

Cachon, P., T. Randall, G.M. Schmidt. 2007. In search of the bullwhip effect. Manufacturing ES Service Operations Management $\mathbf{9}(4) 457$.

Chen, F., Z. Drezner, J.K. Ryan, D. Simchi-Levi. 2000. Quantifying the bullwhip effect in a simple supply chain: The impact of forecasting, lead times, and information. Management science 46(3) $436-443$.

Chen, L, H Lee. 2010. Bullwhip effect measurement and its implications. Fuqua School of Business, Duke University .

Chen, L., H.L. Lee. 2012. Bullwhip effect measurement and its implications. Operations Research 60(4) $771-784$.

Croson, R., K. Donohue. 2005. Upstream versus downstream information and its impact on the bullwhip effect. System Dynamics Review 21(3) 249-260.

Croson, R, K Donohue. 2006. Behavioral causes of the bullwhip effect and the observed value of inventory information. Management Science 52(3) 323-336.

Croson, R., K. Donohue, E. Katok, J. Sterman. Forthcoming. Order stability in supply chains: Coordination risk and the role of coordination stock. Production and Operations Management. . 
Dooley, K.J., T. Yan, S. Mohan, M. Gopalakrishnan. 2010. Inventory management and the bullwhip effect during the 2007-2009 recession: Evidence from the manufacturing sector. Journal of Supply Chain Management 46(1) 12-18.

Escaith, H, N Lindenberg, S Miroudot. 2010. International supply chains and trade elasticity in times of global crisis. World trade organization: Economic research and statistics division (Staff working paper ERSD-2010-08).

Feldstein, M, A Auerbach. 1976. Inventory behavior in durable-goods manufacturing: The targetadjustment model. Brookings Papers on Economic Activity 7(2) 351-408.

Fitzgerald, TJ. 1997. Inventories and the business cycle: an overview. Economic Review-Federal Reserve Bank of Cleveland 33 11-22.

Forrester, J.W. 1958. Industrial dynamics: a major breakthrough for decision makers. Harvard Business Review 36(4) 37-66.

Fransoo, J, M Wouters. 2000. Measuring the bullwhip effect in the supply chain. Supply Chain Management: An international journal 5(2) 78-89.

Gorman, Michael F., James I. Brannon. 2000. Seasonality and the production-smoothing model. International Journal of Production Economics 65(2) 173 - 178.

Homer, Jack B. 1983. Partial-model testing as a validation tool for system dynamics. System Dynamics Review 919-932.

Lee, H.L., V. Padmanabhan, S. Whang. 1997a. The bullwhip effect in supply chains. Sloan management review 38(3) 93-102.

Lee, H.L., V. Padmanabhan, S. Whang. 1997b. Information distortion in a supply chain: the bullwhip effect. Management science 43(4) 546-558.

Lovell, M. 1994. Researching inventories: Why haven't we learned more? International Journal of Production Economics 35 33-41.

Metters, R. 1997. Quantifying the bullwhip effect in supply chains. Journal of Operations Management 15(2) 89-100.

Oliva, R. 2003. Model calibration as a testing strategy for system dynamics models. European Journal of Operational Research 151(3) 552-568.

Oliva, R, J Sterman. 2001. Cutting corners and working overtime: Quality erosion in the service industry. Management Science 47(7) 894-914.

Pesch, Mario, Kai Hoberg. 2013. Inventory management under financial distress: an empirical analysis. Working Paper: Kühne Logistics University .

Rumyantsev, S, S Netessine. 2007. What Can Be Learned from Classical Inventory Models? A CrossIndustry Exploratory Investigation. Manufacturing \&3 Service Operations Management 9(4) 409-429.

Sprague, LG, JG Wacker. 1996. Macroeconomic analyses of inventories: learning from practice. Inter- 
national journal of production economics 45(1-3) 231-237.

Sterman, J. 1989. Modeling managerial behavior: misperceptions of feedback in a dynamic decision making experiment. Management Science 35(3) 321-339.

Sterman, J.D. 2000. Business dynamics: Systems thinking and modeling for a complex world. Irwin/McGraw-Hill.

Sudarsanam, Sudi, Jim Lai. 2001. Corporate financial distress and turnaround strategies: an empirical analysis. British Journal of Management 12(3) 183-199.

Theil, Henri. 1966. Applied economic forecasting,. North-Holland Pub. Co., Amsterdam.

Tversky, A., D. Kahneman. 1974. Judgment under uncertainty: Heuristics and biases. Science 185 1124-1131. 
nr. Year Title

438 Destocking, the Bullwhip Effect, and the Credit Crisis: Empirical Modeling of Supply Chain Dynamics

4372013 Methodological support for business process Redesign in healthcare: a systematic literature review

4362013 Dynamics and equilibria under incremental Horizontal differentiation on the Salop circle

4352013 Analyzing Conformance to Clinical Protocols Involving Advanced Synchronizations

4342013 Models for Ambulance Planning on the Strategic and the Tactical Level

Mode Allocation and Scheduling of Inland Container Transportation: A Case-Study in the

4332013 Netherlands

Socially responsible transportation and lot sizing: 4322013 Insights from multiobjective optimization

4312013 Inventory routing for dynamic waste collection

4302013 Simulation and Logistics Optimization of an Integrated Emergency Post

Last Time Buy and Repair Decisions for Spare 4292013 Parts

A Review of Recent Research on Green Road 4282013 Freight Transportation
Author(s)

Maximiliano Udenio, Jan C. Fransoo, Robert Peels

Rob J.B. Vanwersch, Khurram Shahzad, Irene Vanderfeesten, Kris Vanhaecht, Paul Grefen, Liliane Pintelon, Jan Mendling, Geofridus G. Van Merode, Hajo A. Reijers

B. Vermeulen, J.A. La Poutré, A.G. de Kok

Hui Yan, Pieter Van Gorp, Uzay Kaymak, Xudong Lu, Richard Vdovjak, Hendriks H.M. Korsten, Huilong Duan

J. Theresia van Essen, Johann L. Hurink, Stefan Nickel, Melanie Reuter

Stefano Fazi, Tom Van Woensel, Jan C. Fransoo

Yann Bouchery, Asma Ghaffari, Zied Jemai, Jan Fransoo

Martijn Mes, Marco Schutten, Arturo Pérez Rivera

N.J. Borgman, M.R.K. Mes, I.M.H. Vliegen, E.W. Hans

S. Behfard, M.C. van der Heijden, A. Al Hanbali, W.H.M. Zijm

Emrah Demir, Tolga Bektas, Gilbert Laporte 
4272013 Typology of Repair Shops for Maintenance Spare Parts

4262013 A value network development model and Implications for innovation and production network $\underline{\text { management }}$

4252013 Single Vehicle Routing with Stochastic Demands: Approximate Dynamic Programming

4242013 Influence of Spillback Effect on Dynamic Shortest Path Problems with Travel-Time-Dependent Network Disruptions

4232013 Dynamic Shortest Path Problem with Travel-TimeDependent Stochastic Disruptions: Hybrid Approximate Dynamic Programming Algorithms with a Clustering Approach

4222013 System-oriented inventory models for spare parts

Lost Sales Inventory Models with Batch Ordering 4212013 And Handling Costs

4202013 Response speed and the bullwhip

4192013 Anticipatory Routing of Police Helicopters

4182013 Supply Chain Finance. A conceptual framework to advance research

4172013 Improving the Performance of Sorter Systems By Scheduling Inbound Containers

4162013 Regional logistics land allocation policies: Stimulating spatial concentration of logistics firms

4152013 The development of measures of process harmonization
M.A. Driessen, V.C.S. Wiers,

G.J. van Houtum, W.D. Rustenburg

B. Vermeulen, A.G. de Kok

C. Zhang, N.P. Dellaert, L. Zhao,

T. Van Woensel, D. Sever

Derya Sever, Nico Dellaert, Tom Van Woensel, Ton de Kok

Derya Sever, Lei Zhao, Nico Dellaert, Tom Van Woensel, Ton de Kok

R.J.I. Basten, G.J. van Houtum

T. Van Woensel, N. Erkip, A. Curseu, J.C. Fransoo

Maximiliano Udenio, Jan C. Fransoo, Eleni Vatamidou, Nico Dellaert

Rick van Urk, Martijn R.K. Mes, Erwin W. Hans

Kasper van der Vliet, Matthew J. Reindorp, Jan C. Fransoo

S.W.A. Haneyah, J.M.J. Schutten, K. Fikse

Frank P. van den Heuvel, Peter W. de Langen, Karel $\mathrm{H}$. van Donselaar, Jan C. Fransoo

Heidi L. Romero, Remco M. Dijkman, Paul W.P.J. Grefen, Arjan van Weele 
4142013 BASE/X. Business Agility through CrossOrganizational Service Engineering

4132013 The Time-Dependent Vehicle Routing Problem with Soft Time Windows and Stochastic Travel $\underline{\text { Times }}$

4122013 Clearing the Sky - Understanding SLA Elements in Cloud Computing

4112013 Approximations for the waiting time distribution In an M/G/C priority queue

4102013

To co-locate or not? Location decisions and logistics concentration areas

4092013 The Time-Dependent Pollution-Routing Problem

$4082013 \frac{\text { Scheduling the scheduling task: A time }}{\text { Management perspective on scheduling }}$

4072013 Clustering Clinical Departments for Wards to Achieve a Prespecified Blocking Probability

$4062013 \frac{\text { MyPHRMachines: Personal Health Desktops }}{\text {. }}$ in the Cloud

4052013 Maximising the Value of Supply Chain Finance

$4042013 \frac{\text { Reaching } 50 \text { million nanostores: retail }}{\text { distribution in emerging megacities }}$

$4032013 \frac{\text { A Vehicle Routing Problem with Flexible Time }}{\text { Windows }}$
Paul Grefen, Egon Lüftenegger, Eric van der Linden, Caren Weisleder

Duygu Tas, Nico Dellaert, Tom van Woensel, Ton de Kok

Marco Comuzzi, Guus Jacobs, Paul Grefen
A. Al Hanbali, E.M. Alvarez, M.C. van der van der Heijden

Frank P. van den Heuvel, Karel H. van Donselaar, Rob A.C.M. Broekmeulen, Jan C. Fransoo, Peter W. de Langen

Anna Franceschetti, Dorothée Honhon, Tom van Woensel, Tolga Bektas, GilbertLaporte.

J.A. Larco, V. Wiers, J. Fransoo

J. Theresia van Essen, Mark van Houdenhoven, Johann L. Hurink

Pieter Van Gorp, Marco Comuzzi

Kasper van der Vliet, Matthew J. Reindorp, Jan C. Fransoo

Edgar E. Blanco, Jan C. Fransoo

Duygu Tas, Ola Jabali, Tom van Woensel 
4022013 The Service Dominant Business Model: A

Service Focused Conceptualization

4012012 Relationship between freight accessibility and Logistics employment in US counties

4002012 A Condition-Based Maintenance Policy for MultiComponent Systems with a High Maintenance Setup Cost

3992012 A flexible iterative improvement heuristic to Support creation of feasible shift rosters in Self-rostering

Scheduled Service Network Design with 3982012 Synchronization and Transshipment Constraints For Intermodal Container Transportation Networks

3972012 Destocking, the bullwhip effect, and the credit Crisis: empirical modeling of supply chain Dynamics $3962012 \underline{\text { Vehicle routing with restricted loading }}$

3952012 Service differentiation through selective lateral transshipments

3942012 A Generalized Simulation Model of an Integrated Emergency Post

3932012 Business Process Technology and the Cloud: Defining a Business Process Cloud Platform

3922012 Vehicle Routing with Soft Time Windows and Stochastic Travel Times: A Column Generation And Branch-and-Price Solution Approach
Egon Lüftenegger, Marco Comuzzi, Paul Grefen, Caren Weisleder

Frank P. van den Heuvel, Liliana Rivera,Karel H. van Donselaar, Ad de Jong, Yossi Sheffi, Peter W. de Langen, Jan C.Fransoo

Qiushi Zhu, Hao Peng, Geert-Jan van Houtum

E. van der Veen, J.L. Hurink, J.M.J. Schutten, S.T. Uijland

K. Sharypova, T.G. Crainic, T. van Woensel, J.C. Fransoo

Maximiliano Udenio, Jan C. Fransoo, Robert Peels

J. Gromicho, J.J. van Hoorn, A.L. Kok J.M.J. Schutten

E.M. Alvarez, M.C. van der Heijden, I.M.H. Vliegen, W.H.M. Zijm

Martijn Mes, Manon Bruens

Vasil Stoitsev, Paul Grefen

D. Tas, M. Gendreau, N. Dellaert, T. van Woensel, A.G. de Kok 
3912012 Improve OR-Schedule to Reduce Number of $\underline{\text { Required Beds }}$

3902012 How does development lead time affect performance over the ramp-up lifecycle?

3892012 Evidence from the consumer electronics industry

3882012 The Impact of Product Complexity on RampUp Performance

3872012 Co-location synergies: specialized versus diverse logistics concentration areas

3862012 Proximity matters: Synergies through co-location of logistics establishments

3852012 Spatial concentration and location dynamics in logistics:the case of a Dutch province $3842012 \frac{\text { FNet: An Index for Advanced Business Process }}{\text { Querying }}$

3832012 Defining Various Pathway Terms

$3822012 \frac{\text { The Service Dominant Strategy Canvas: }}{\text { Defining and Visualizing a Service Dominant }}$

Strategy through the Traditional Strategic Lens

$3812012 \frac{\text { A Stochastic Variable Size Bin Packing Problem }}{\underline{\text { With Time Constraints }}}$

$3802012 \underline{\text { Coordination and Analysis of Barge Container }}$
J.T. v. Essen, J.M. Bosch, E.W. Hans, M. v. Houdenhoven, J.L. Hurink

Andres Pufall, Jan C. Fransoo, Ad de Jong

Andreas Pufall, Jan C. Fransoo, Ad de Jong, Ton de Kok

Frank P.v.d. Heuvel, Peter W.de Langen,

Karel H. v. Donselaar, Jan C. Fransoo

Frank P.v.d. Heuvel, Peter W.de Langen,

Karel H. v.Donselaar, Jan C. Fransoo

Frank P. v.d.Heuvel, Peter W.de Langen,

Karel H.v. Donselaar, Jan C. Fransoo

Zhiqiang Yan, Remco Dijkman, Paul Grefen

W.R. Dalinghaus, P.M.E. Van Gorp

Egon Lüftenegger, Paul Grefen, Caren Weisleder

Stefano Fazi, Tom van Woensel, Jan C. Fransoo

K. Sharypova, T. van Woensel, J.C. Fransoo

Frank P. van den Heuvel, Peter W. de Langen, Karel $\mathrm{H}$. van Donselaar, Jan 
C.

Fransoo

Proximity matters: Synergies through co-location 3792012 of logistics establishments

Heidi Romero, Remco Dijkman, Paul Grefen, Arjan van Weele

A literature review in process harmonization: a 3782012 conceptual framework

\section{A Generic Material Flow Control Model for}

3772012 Two Different Industries

$3752012 \frac{\text { Improving the performance of sorter systems by }}{\text { scheduling }}$ scheduling inbound containers

3742012 Strategies for dynamic appointment making by container terminals

MyPHRMachines: Lifelong Personal Health

3732012 Records in the Cloud

3722012 Service differentiation in spare parts supply $\underline{\text { through dedicated stocks }}$

3712012 Spare parts inventory pooling: how to share the benefits

S.W.A. Haneya, J.M.J. Schutten, P.C. Schuur, W.H.M. Zijm

H.G.H. Tiemessen, M. Fleischmann, G.J. van Houtum, J.A.E.E. van Nunen, E. Pratsini

Albert Douma, Martijn Mes

Pieter van Gorp, Marco Comuzzi

E.M. Alvarez, M.C. van der Heijden, W.H.M. Zijm

Frank Karsten, Rob Basten

X.Lin, R.J.I. Basten, A.A. Kranenburg, G.J. van Houtum

Martijn Mes

J. Arts, S.D. Flapper, K. Vernooij $3692012 \frac{\text { Using Simulation to Assess the Opportunities of }}{\text { Dynamic Waste Collection }}$

3682011 Aggregate overhaul and supply chain planning for rotables

J.T. van Essen, J.L. Hurink, W. Hartholt,

B.J. van den Akker

3672011 Operating Room Rescheduling

Kristel M.R. Hoen, Tarkan Tan, Jan C. Fransoo, Geert-Jan van Houtum

3662011 Switching Transport Modes to Meet Voluntary Carbon Emission Targets

Elisa Alvarez, Matthieu van der Heijden 
3652011 On two-echelon inventory systems with Poisson demand and lost sales

3642011 Minimizing the Waiting Time for Emergency Surgery

3632011 Vehicle Routing Problem with Stochastic Travel Times Including Soft Time Windows and Service Costs

3622011 A New Approximate Evaluation Method for TwoEchelon Inventory Systems with Emergency Shipments

3612011

Approximating Multi-Objective Time-Dependent Optimization Problems

3602011 Branch and Cut and Price for the Time Dependent Vehicle Routing Problem with Time Window

3592011

Analysis of an Assemble-to-Order System with Different Review Periods

3582011

Interval Availability Analysis of a Two-Echelon, Multi-Item System

3572011

Carbon-Optimal and Carbon-Neutral Supply

Chains

3562011

Generic Planning and Control of Automated

Material Handling Systems: Practical

Requirements Versus Existing Theory

3552011

Last time buy decisions for products sold under warranty

3542011

3532011

Spatial concentration and location dynamics in logistics: the case of a Dutch provence

3522011

Identification of Employment Concentration Areas

BOMN 2.0 Execution Semantics Formalized as Graph Rewrite Rules: extended version

3512011

Resource pooling and cost allocation among independent service providers
J.T. van Essen, E.W. Hans, J.L. Hurink, A. Oversberg

Duygu Tas, Nico Dellaert, Tom van Woensel, Ton de Kok

Erhun Özkan, Geert-Jan van Houtum, Yasemin Serin

Said Dabia, El-Ghazali Talbi, Tom Van Woensel, Ton de Kok

Said Dabia, Stefan Röpke, Tom Van Woensel, Ton de Kok

A.G. Karaarslan, G.P. Kiesmüller, A.G. de Kok

Ahmad Al Hanbali, Matthieu van der Heijden

Felipe Caro, Charles J. Corbett, Tarkan Tan, Rob Zuidwijk

Sameh Haneyah, Henk Zijm, Marco Schutten, Peter Schuur

M. van der Heijden, B. Iskandar

Frank P. van den Heuvel, Peter W. de Langen, Karel H. van Donselaar, Jan C. Fransoo

Frank P. van den Heuvel, Peter W. de Langen, Karel $\mathrm{H}$. van Donselaar, Jan C. Fransoo

Pieter van Gorp, Remco Dijkman

Frank Karsten, Marco Slikker, GeertJan van Houtum

E. Lüftenegger, S. Angelov, P. Grefen 
3502011

A Framework for Business Innovation Directions

3492011

The Road to a Business Process Architecture: An 3482011 Overview of Approaches and their Use

Effect of carbon emission regulations on transport 3472011 mode selection under stochastic demand

An improved MIP-based combinatorial approach 3462011

for a multi-skill workforce scheduling problem

An approximate approach for the joint problem of level of repair analysis and spare parts stocking

3452011

Joint optimization of level of repair analysis and spare parts stocks

3442011

Inventory control with manufacturing lead time flexibility

3432011

Analysis of resource pooling games via a new

3422011 extenstion of the Erlang loss function

Vehicle refueling with limited resources

3412010

Optimal Inventory Policies with Non-stationary

Supply Disruptions and Advance Supply Information

3392010

Redundancy Optimization for Critical Components in High-Availability Capital Goods

3382010

Analysis of a two-echelon inventory system with two supply modes

3352010

Analysis of the dial-a-ride problem of Hunsaker and Savelsbergh

3342010

Attaining stability in multi-skill workforce scheduling A.J.M.M. Weijters, J.T.S. Ribeiro

Remco Dijkman, Irene Vanderfeesten, Hajo A. Reijers

\section{K.M.R. Hoen, T. Tan, J.C. Fransoo}

G.J. van Houtum

\section{Murat Firat, Cor Hurkens}

R.J.I. Basten, M.C. van der Heijden,

J.M.J. Schutten

R.J.I. Basten, M.C. van der Heijden, J.M.J. Schutten

Ton G. de Kok

Frank Karsten, Marco Slikker, GeertJan van Houtum

Murat Firat, C.A.J. Hurkens, Gerhard J. Woeginger

Bilge Atasoy, Refik Güllü, TarkanTan

Kurtulus Baris Öner, Alan Scheller-Wolf Geert-Jan van Houtum

Murat Firat, Gerhard J. Woeginger

Murat Firat, Cor Hurkens 
Flexible Heuristics Miner (FHM)

3322010

An exact approach for relating recovering surgical patient workload to the master surgical schedule

3312010 Efficiency evaluation for pooling resources in health care

3302010 The Effect of Workload Constraints in Mathematical Programming Models for Production Planning

3292010 Using pipeline information in a multi-echelon spare parts inventory system

3282010 Reducing costs of repairable spare parts supply systems via dynamic scheduling

3272010 Identification of Employment Concentration and Specialization Areas: Theory and Application

3262010 A combinatorial approach to multi-skill workforce scheduling

3252010 Stability in multi-skill workforce scheduling

3242010 Maintenance spare parts planning and control: A framework for control and agenda for future research $3232010 \frac{\text { Near-optimal heuristics to set base stock levels in }}{\text { a two-echelon distribution network }}$

3222010 Inventory reduction in spare part networks by selective throughput time reduction

3212010 The selective use of emergency shipments for service-contract differentiation
Hans, J.L. Hurink, W.A.M. van Lent, W.H. van Harten

Peter T. Vanberkel, Richard J.

Boucherie, Erwin W. Hans, Johann L. Hurink, Nelly Litvak

M.M. Jansen, A.G. de Kok, I.J.B.F. Adan

Christian Howard, Ingrid Reijnen, Johan Marklund, Tarkan Tan

H.G.H. Tiemessen, G.J. van Houtum

F.P. van den Heuvel, P.W. de Langen, K.H. van Donselaar, J.C. Fransoo

Murat Firat, Cor Hurkens

Murat Firat, Cor Hurkens, Alexandre Laugier

M.A. Driessen, J.J. Arts, G.J. v. Houtum, W.D. Rustenburg, B. Huisman

R.J.I. Basten, G.J. van Houtum

M.C. van der Heijden, E.M. Alvarez, J.M.J. Schutten

E.M. Alvarez, M.C. van der Heijden, W.H. Zijm

B. Walrave, K. v. Oorschot, A.G.L. Romme 
Heuristics for Multi-Item Two-Echelon Spare Parts Inventory Control Problem with Batch Ordering in

the Central Warehouse

3192010

Preventing or escaping the suppression

mechanism: intervention conditions

3182010

Hospital admission planning to optimize major resources utilization under uncertainty

Nico Dellaert, Jully Jeunet.

R. Seguel, R. Eshuis, P. Grefen.

Tom Van Woensel, Marshall L. Fisher,

3172010 Minimal Protocol Adaptors for Interacting Services Jan C. Fransoo.

Teaching Retail Operations in Business and

3162010 Engineering Schools

3152010 Design for Availability: Creating

Transforming Process Models: executable rewrite 3142010

rules versus a formalized Java program

Getting trapped in the suppression of exploration: 3132010

A simulation model

A Dynamic Programming Approach to MultiObjective Time-Dependent Capacitated Single Vehicle Routing Problems with Time Windows

Tales of a So(u)rcerer: Optimal Sourcing Decisions

3122010 Under Alternative Capacitated Suppliers and General Cost Structures

In-store replenishment procedures for perishable

3112010 inventory in a retail environment with handling costs and storage constraints

3102010 The state of the art of innovation-driven business models in the financial services industry

Lydie P.M. Smets, Geert-Jan van Houtum, Fred Langerak.

Pieter van Gorp, Rik Eshuis.

Bob Walrave, Kim E. van Oorschot, A Georges L. Romme

S. Dabia, T. van Woensel, A.G. de Kok Osman Alp, Tarkan Tan

R.A.C.M. Broekmeulen, C.H.M. Bakx

E. Lüftenegger, S. Angelov, E. van der Linden, P. Grefen

R. Seguel, P. Grefen, R. Eshuis

3092010 Design of Complex Architectures Using a Three Dimension Approach: the CrossWork Case

3082010 Effect of carbon emission regulations on transport mode selection in supply chains

K.M.R. Hoen, T. Tan, J.C. Fransoo, G.J. van Houtum

$3072010 \frac{\text { Interaction between intelligent agent strategies for }}{\text { real-time transportation planning }}$

3062010 Internal Slackening Scoring Methods

$3052010 \frac{\text { Vehicle Routing with Traffic Congestion and }}{\text { Drivers' Driving and Working Rules }}$

3042010 Practical extensions to the level of repair analysis

Martijn Mes, Matthieu van der Heijden, Peter Schuur

Marco Slikker, Peter Borm, René van den Brink

A.L. Kok, E.W. Hans, J.M.J. Schutten, W.H.M. Zijm

R.J.I. Basten, M.C. van der Heijden, J.M.J. Schutten

3032010 Ocean Container Transport: An Underestimated 
and Critical Link in Global Supply Chain

Performance

$3022010 \frac{\text { Capacity reservation and utilization for a }}{\text { manufacturer with uncertain capacity and demand }}$

Y. Boulaksil; J.C. Fransoo; T. Tan

3002009 Spare parts inventory pooling games

F.J.P. Karsten; M. Slikker; G.J. van Houtum

$2992009 \frac{\text { Capacity flexibility allocation in an outsourced }}{\text { supply chain }}$ supply chain with reservation

Y. Boulaksil, M. Grunow, J.C. Fransoo $2982010 \frac{\text { An optimal approach for the joint problem of level }}{\text { of repair analysis and spare parts stocking }}$

Responding to the Lehman Wave: Sales

2972009 Forecasting and Supply Management during the Credit Crisis

2962009 An exact approach for relating recovering surgical patient workload to the master surgical schedule

R.J.I. Basten, M.C. van der Heijden, J.M.J. Schutten

Robert Peels, Maximiliano Udenio, Jan C. Fransoo, Marcel Wolfs, Tom Hendrikx

Peter T. Vanberkel, Richard J.

Boucherie, Erwin W. Hans, Johann L. Hurink, Wineke A.M. van Lent, Wim H. van Harten

An iterative method for the simultaneous

2952009 optimization of repair decisions and spare parts stocks

2942009 Fujaba hits the Wall(-e)

$2932009 \frac{\text { Implementation of a Healthcare Process in Four }}{\text { Different Workflow Systems }}$

R.J.I. Basten, M.C. van der Heijden, J.M.J. Schutten

Pieter van Gorp, Ruben Jubeh, Bernhard Grusie, Anne Keller

R.S. Mans, W.M.P. van der Aalst, N.C. Russell, P.J.M. Bakker

2922009 Business Process Model Repositories - Framework Zhiqiang Yan, Remco Dijkman, Paul and Survey

Grefen

2912009 Efficient Optimization of the Dual-Index Policy Using Markov Chains

Joachim Arts, Marcel van Vuuren, Gudrun Kiesmuller

2902009 Hierarchical Knowledge-Gradient for Sequential Sampling

Analyzing combined vehicle routing and break

2892009 scheduling from a distributed decision making perspective

2882009 Anticipation of lead time performance in Supply Chain Operations Planning

Martijn R.K. Mes; Warren B. Powell; Peter I. Frazier

C.M. Meyer; A.L. Kok; H. Kopfer; J.M.J. Schutten

Michiel Jansen; Ton G. de Kok; Jan C. Fransoo

$2872009 \frac{\text { Inventory Models with Lateral Transshipments: A }}{\text { Review }}$

Colin Paterson; Gudrun Kiesmuller; Ruud Teunter; Kevin Glazebrook

2862009 Efficiency evaluation for pooling resources in

$2852009 \frac{\text { A Survey of Health Care Models that Encompass }}{\text { Multiple Departments }}$

P.T. Vanberkel; R.J. Boucherie; E.W. Hans; J.L. Hurink; N. Litvak

P.T. Vanberkel; R.J. Boucherie; E.W. Hans; J.L. Hurink; N. Litvak

$2842009 \frac{\text { Supporting Process Control in Business }}{\text { Collaborations }}$

S. Angelov; K. Vidyasankar; J. Vonk; P. Grefen

2832009 Inventory Control with Partial Batch Ordering

O. Alp; W.T. Huh; T. Tan

$2822009 \frac{\text { Translating Safe Petri Nets to Statecharts in a }}{\text { Structure-Preserving Way }}$

R. Eshuis 
2812009

The link between product data model and process model

J.J.C.L. Vogelaar; H.A. Reijers

2802009 Inventory planning for spare parts networks with delivery time requirements

I.C. Reijnen; T. Tan; G.J. van Houtum

2792009 Co-Evolution of Demand and Supply under Competition

B. Vermeulen; A.G. de Kok

Toward Meso-level Product-Market Network

B. Vermeulen, A.G. de Kok 2782010 Indices for Strategic Product Selection and

(Re)Design Guidelines over the Product Life-Cycle

An Efficient Method to Construct Minimal Protocol 2772009 Adaptors

2762009 Coordinating Supply Chains: a Bilevel Programming Approach

2752009 Inventory redistribution for fashion products under demand parameter update

R. Seguel, R. Eshuis, P. Grefen

Ton G. de Kok, Gabriella Muratore

G.P. Kiesmuller, S. Minner

2742009 Comparing Markov chains: Combining aggregation and precedence relations applied to sets of states

A. Busic, I.M.H. Vliegen, A. SchellerWolf

2732009 Separate tools or tool kits: an exploratory study of engineers' preferences

I.M.H. Vliegen, P.A.M. Kleingeld, G.J. van Houtum

An Exact Solution Procedure for Multi-Item Two-

2722009 Echelon Spare Parts Inventory Control Problem with Batch Ordering

Engin Topan, Z. Pelin Bayindir, Tarkan Tan

C.M. Meyer, H. Kopfer, A.L. Kok, M. Schutten

2712009 Distributed Decision Making in Combined Vehicle Routing and Break Scheduling

Dynamic Programming Algorithm for the Vehicle

2702009 Routing Problem with Time Windows and EC Social Legislation

A.L. Kok, C.M. Meyer, H. Kopfer, J.M.J. Schutten

Remco Dijkman, Marlon Dumas,

$2692009 \frac{\text { Similarity of Business Process Models: Metics and }}{\text { Evaluation }}$ Boudewijn van Dongen, Reina Kaarik, Jan Mendling

2672009 Vehicle routing under time-dependent travel times:

A.L. Kok, E.W. Hans, J.M.J. Schutten

$2662009 \frac{\text { Restricted dynamic programming: a flexible }}{\text { framework for solving realistic VRPs }}$

J. Gromicho; J.J. van Hoorn; A.L. Kok; J.M.J. Schutten;

Working Papers published before 2009 see: http://beta.ieis.tue.nl 